\title{
Hair Washing Formulations from Aloe elegans Todaro Gel: The Potential for Making Hair Shampoo
}

\author{
Desta Berhe Sbhatu ${ }^{D},{ }^{1}$ Goitom Gebreyohannes Berhe, ${ }^{1}$ Abadi Gebreyesus Hndeya, ${ }^{1}$ \\ Asmael Abdu, ${ }^{1}$ Afework Mulugeta, ${ }^{1}$ Haftom Baraki Abraha, ${ }^{1}$ Micheale Yifter Weldemichael $\mathbb{D},{ }^{1}$ \\ Hailekiros Tadesse Tekle, ${ }^{1}$ Haftay Abadi Gebru, ${ }^{2}$ Molla Gereme Taye, \\ and Haileselassie Gebremeskel Kidanemariam ${ }^{3}$
}

${ }^{1}$ Mekelle University, P.O. Box 231/1632, Mekelle, Ethiopia

${ }^{2}$ Tigrai Biotechnology Center Pvt. Ltd. Co., Mekelle, Ethiopia

${ }^{3}$ Mekhoni Agricultural Research Center, P.O. Box 71, Mekhoni, Ethiopia

Correspondence should be addressed to Desta Berhe Sbhatu; desta.sbhatu@mu.edu.et

Received 4 June 2020; Revised 8 August 2020; Accepted 12 August 2020; Published 1 September 2020

Academic Editor: Srinivas Mutalik

Copyright (c) 2020 Desta Berhe Sbhatu et al. This is an open access article distributed under the Creative Commons Attribution License, which permits unrestricted use, distribution, and reproduction in any medium, provided the original work is properly cited.

\begin{abstract}
This study aimed to describe the gross phytochemical constituents of Aloe elegans Todaro gel and evaluate the characteristics and quality of lab-made hair washing formulations prepared from the gel to show its potential in formulating hair washing shampoos. A. elegans gel mass was prepared from mature, healthy leaves collected from natural stand. Samples of $100 \%$ methanol extract of the gel were subjected to standard phytochemical screening and gas chromatography-mass spectroscopy (GC-MS) analysis. Five hair washing formulations (Fs) were, likewise, prepared by mixing $4.0-10.0 \mathrm{~mL}$ of gel with one $(0.05 \mathrm{~mL})$ to two $(0.10 \mathrm{~mL})$ drops of six synthetic and natural ingredients, namely, coconut oil, jojoba oil, olive oil, pure glycerin oil, lemon juice, and vitamin E. The gel to the total ingredient ratios $(\mathrm{v} / \mathrm{v})$ of the five formulations were $93: 7\left(\mathrm{~F}_{1}\right)$, $94.5: 5.5\left(\mathrm{~F}_{2}\right), 96.4: 3.6\left(\mathrm{~F}_{3}\right)$, and $96.6: 3.4\left(\mathrm{~F}_{4}\right.$ and $\left.\mathrm{F}_{5}\right)$. The formulations were evaluated using sensory inspection and common physicochemical methods. The phytochemical screening and GC-MS analysis revealed that A. elegans gel is the source of important chemical constituents used in the formulation of shampoos and similar products including saponins, capric acid, lauric acid, myristic acid, palmitic acid, linoleic acid, stearic acid, and phytol. Lab-made A. elegans hair washing formulations, especially those with $96.4-96.6 \%$ gel, were found to have similar characteristics and qualities with a common marketed shampoo. All the formulations were turbid with characteristic odor as the marketed shampoo. The $\mathrm{pH}$ values of the hair washing formulations (6.4-4.6) were comparable to those of the marketed shampoo (6.7). Formulations with higher proportion of gel had better foam stability, higher solid content (26-29\%), higher surface tension (33-38 dynes/cm), shorter wetting time (150-160 sec), equivalent viscosities (26.45-26.73 poise), and conditioning performance than the marketed shampoo. These findings demonstrate that $A$. elegans gel mass can be used in the formulation of good-quality hair washing shampoos. We recommend future studies that aim to develop the phytochemical profile of the plant and a refined protocol of hair washing shampoo formulation.
\end{abstract}

\section{Introduction}

The genus Aloe L. (Aloaceae) comprises more than 500 species of succulent flowering plants. Aloes are native to many parts of Africa and Madagascar, the Mediterranean, Arabian Peninsula, South and Central America, the Rio Grande Valley of South Texas and Florida, Southern
California and Mexico, the Pacific Rim Countries, India, the Caribbean, and Australia $[1,2]$. They thrive in a range of latitudinal and altitudinal zones and diversity of habitats such as forests, wooded-grasslands, woodlands, rocky expanses, mountain tops and cliffs, beaches, waterfalls, and many other ecological zones with extreme environmental and soil conditions [3]. Fifty (50) species of Aloe are known 
and described in the flora of Ethiopia and Eritrea so far; 31 of them are endemic and restricted to very small areas $[3,4]$.

The Tigrai floristic region of the flora of Ethiopian and Eritrea is home to many Aloe species including $A$. adigratana Reynolds, A. camperi Schweinfurth, A. elegans Todaro, A. macrocarpa Todaro, A. monticola Reynolds, A. percrassa Todaro, A. steudneri Schweinfurth, and A. trichosantha Berger. A. elegans grows in a range of habitats in Tigrai, Wollo, Gojjam, and Shewa floristic regions of Ethiopia and Eritrea from 1,500 to 2,400 meters. The plant is the second or third most abundant Aloe species in Tigrai. It flowers from September to December and occasionally from March to May [3]. It is planted as fence of farm plots, backyards, homesteads, churchyards, forest enclosures, and footpaths in Tigrai. The conservation and sustainable use of this plant depends on the knowledge of its use and potential. The plant is included in the International Union for Conservation of Nature (IUCN) List of Threatened Species since 2013 [5].

Aloes have been all-purpose plants over many millennia across all civilizations. They are endowed with a range of chemical constituents that can be used in preparing beauty and cosmetic, medicinal and pharmaceutical, personal care and toiletry products, and bittering agents in alcoholic drinks. They are also grown as ornamental plants $[6,7]$. Furthermore, aloes have been used in preparing many traditional remedies for healing wounds, anesthetizing tissues, stopping fungal, viral, and bacterial growths, improving blood flow, and acting as anti-inflammatory, antiaging, and antiallergic agents [6, 8]. Many varieties of $A$. vera L. ( $A$. barbadensis) and few other species A. arborescens, $A$. sinkatana, A. ferox, and A. pulcherrima are extensively studied and are known to be rich sources of essential oils, fatty acids, alkaloids, and phenolic compounds that have a range of therapeutic and health benefits to humans [9-14]. Extracts and isolates of Aloe species are known to exhibit antioxidant, anticancer, anti-inflammatory, and antimicrobial activities. Thus, their economic potentials and applications in cosmetic and personal care, nutriceutical, pharmaceutical, and food and beverage industries are increasing [10,15-17]. However, there are very limited studies on the environmental and commercial potentials of the majority of the aloes.

Many researchers explored into the phytochemistry, biocidal activities, and pharmaceutical properties in some Ethiopian aloes including $A$. adigratana, $A$. citrina, A. debrana, A. elegans, A. harlana, A. megalacantha, A. otallensis, A. percrassa, A. pulcherrima, A. rivae, and A. sinana [18-30]. However, the studies on Ethiopian aloes, including $A$. elegans, were isolated endeavors without continuity. One study with whole tissues of $A$. elegans leaf revealed that it is a good source of phenols, flavonoids, tannins, terpenoids, saponins, and glycosides with antifungal and antibacterial activities [21]. Another study showed that the plant is a useful source of traditional remedies against abdominal pain, malaria, diabetics, impotence, and many other human ailments in Tigrai (Ethiopia) and Eritrea [31, 32]. Moreover, it is used in the preparation of traditional hair washing shampoos by local people in Eritrea [31]. The present study aimed to determine the phytochemistry of $A$. elegans gel and evaluate the characteristics of lab-made hair washing formulations of the gel to demonstrate its potential for making hair washing and conditioning shampoo.

\section{Materials and Methods}

2.1. Collection and Preparation of Plant Specimens. Healthy and mature leaves of $A$. elegans were collected from wild stand at north of Sele (at about $86 \mathrm{~km}$ on the MekelleAbbiyi Addi highway; latitude/longitude: 13.560/39.026; altitude: 1,694 m) on 21 December 2018. Collection of plant materials by natives (Ethiopians) for research is granted by Article 15, Clause 1, of the Access to Genetic Resources and Community Knowledge and Community Rights Proclamation of the Federal Democratic Republic of Ethiopia (No. 482/2006). Specimens of the plant were identified by the National Herbarium (ETH), the Department of Biology, Addis Ababa University (Ethiopia). The leaves were rinsed with running tap water to remove any dirt and soil. The leaf (i.e., outer green skin) and the gel (i.e., inner gelatinous mass) were separated by peeling the skin off with a scalpel knife. The mass of gel was dried in shade at room temperature for 18 days. The dried mass of gel was then pulverized into powder using an electrical grinder and stored in a sealed container until used for phytochemical study.

2.2. Phytochemistry of Gel Extracts. Powder of A. elegans gel was extracted by $100 \%$ methanol using the continuous hot percolation method in Soxhlet apparatus for 18 hours. The extract was concentrated in a rotary evaporator into brown liquid and kept at $4^{\circ} \mathrm{C}$ in a deep freezer. Samples of the extract were taken out and subjected to phytochemical screening using the standard tests for alkaloids (Wagner test) [33], anthraquinones (Borntrager's test) [34], flavonoids (lead acetate test) [35], saponins (Froth test) [36], tannins (ferric chloride test) [37], and terpenoids (Salkowski test) [36].

2.3. Gas Chromatography-Mass Spectrometry (GC-MS) Analysis. Likewise, samples of the gel extract were sent to JIJE LOBOGLASS Plc.-a certified analytical laboratory in Addis Ababa, Ethiopia-for gas chromatography-mass spectroscopy (GC-MS) analysis. The instrument control parameters of the GC-MS are given in Appendix. The GCMS analysis was carried out to determine the essential oil and fatty acid methyl ester contents of the gel.

\subsection{Preparation of Hair Washing Formulations from} A. elegans Gel. Five lab-made hair washing formulations were prepared by mixing $A$. elegans gel mass with six natural and formulated ingredients. The ingredients were coconut oil, jojoba oil, lemon juice, olive oil, pure glycerin oil, and vitamin $\mathrm{E}$ (Table 1).

The gel masses were mixed with the ingredients according to the ratio indicated in Table 2 to prepare enough volume hair washing formulations [38-40]. Then, mixtures 
TABLE 1: Ingredients used in preparing lab-made hair washing formulations from A. elegans gel.

\begin{tabular}{|c|c|c|}
\hline Generic name & Manufacturer & Biological applications \\
\hline A. elegans gel & - & $\begin{array}{l}\text { Repairs, strengthens, hydrates, and softens hair; makes hair look and feel healthier; heals wounds; } \\
\text { acts as natural surfactant }\end{array}$ \\
\hline Coconut oil & C.B.C., Malaysia & Prevents protein loss in hair; moist \\
\hline & & \\
\hline Lemon juice & Fresh lab extract & $\begin{array}{c}\text { Acts as natural antioxidant, chelating, and antidandruff agent; maintains the } \mathrm{pH} \text { of the acidic } \\
\text { formulation }\end{array}$ \\
\hline & & Moisturizes hair; minimizes scalp irritation; reduces dandruff \\
\hline $\begin{array}{l}\text { Pure glycerin } \\
\text { oil }\end{array}$ & $\begin{array}{l}\text { LFRESSH-Eurogulf, } \\
\text { UAE }\end{array}$ & Hydrates skin; enhances cell maturation; removes dandruff \\
\hline Vitamin E & $\begin{array}{c}\text { Fruit of the Earth, } \\
\text { USA }\end{array}$ & $\begin{array}{c}\text { Supports scalp; gives hair strong base to grow; reduces oxidative stress; preserves protective lipid } \\
\text { layer }\end{array}$ \\
\hline
\end{tabular}

TABle 2: Preparation of hair washing formulations from A. elegans gel.

\begin{tabular}{|c|c|c|c|c|c|c|c|c|c|c|c|}
\hline \multirow{3}{*}{ Ingredients } & \multirow{3}{*}{$\mathrm{UoM}^{*}$} & \multicolumn{10}{|c|}{ Formulations } \\
\hline & & \multicolumn{2}{|c|}{$\mathrm{F}_{1}$} & \multicolumn{2}{|c|}{$\mathrm{F}_{2}$} & \multicolumn{2}{|c|}{$\mathrm{F}_{3}$} & \multicolumn{2}{|c|}{$\mathrm{F}_{4}$} & \multicolumn{2}{|c|}{$\mathrm{F}_{5}$} \\
\hline & & Vol. & $\% \mathrm{v} / \mathrm{v}$ & Vol. & $\% \mathrm{v} / \mathrm{v}$ & Vol. & $\% \mathrm{v} / \mathrm{v}$ & Vol. & $\% \mathrm{v} / \mathrm{v}$ & Vol. & $\% \mathrm{v} / \mathrm{v}$ \\
\hline A. elegans gel & $\mathrm{mL}$ & 4.0 & 93.0 & 6 & 94.5 & 8 & 96.4 & 10 & 96.6 & 10 & 96.6 \\
\hline Coconut oil & gtt. & 1 & 1.16 & 1 & 0.79 & 1 & 0.60 & 1 & 0.48 & 2 & 0.97 \\
\hline Olive oil & gtt. & 1 & 1.16 & 2 & 1.57 & 1 & 0.60 & 2 & 0.97 & 1 & 0.48 \\
\hline Jojoba oil & gtt. & 1 & 1.16 & 1 & 0.79 & 1 & 0.60 & 1 & 0.48 & 1 & 0.48 \\
\hline Glycerin oil & gtt. & 1 & 1.16 & 1 & 0.79 & 1 & 0.60 & 1 & 0.48 & 1 & 0.48 \\
\hline Vitamin E & gtt. & 1 & 1.16 & 1 & 0.79 & 1 & 0.60 & 1 & 0.48 & 1 & 0.48 \\
\hline Lemon juice & gtt. & 1 & 1.16 & 1 & 0.79 & 1 & 0.60 & 1 & 0.48 & 1 & 0.48 \\
\hline
\end{tabular}

*UoM, unit of measurement; mL: milliliter; gtt.: drop $(0.05 \mathrm{~mL})$.

were homogenized one by one with magnetic stirrer at $400 \mathrm{rpm}$ for $30 \mathrm{~min}$ at $30^{\circ} \mathrm{C}$, and white smooth formulations were obtained. Finally, the formulations were transferred into labeled collapsible plastic tubes and kept at room temperature for physicochemical evaluation.

\subsection{Evaluation of the Characteristics of the Hair Washing} Formulations. The formulations were evaluated via sensory inspection and physical assessment methods based on procedures developed and used by many researchers against a marketed shampoo (product name: Aloe Vera Hair Shampoo; producer: Perfect Cosmetics, UAE; size: $5.5 \mathrm{~mL}$; description: natural blend of Aloe vera extract and moisturizers; manufactured: 02/2018; expiry: 02/2021) [38-45].

2.5.1. Sensory Inspection. The physical appearance of the lab-made formulations was evaluated based their color, clarity, odor, consistency, and spreadability. The visual inspection of each formulation was carried out by three randomly selected volunteering students at room temperature.

2.5.2. Determination of $p H$. A $10 \%(\mathrm{v} / \mathrm{v})$ solution was prepared from each hair washing formulation using sterile distilled water. The $\mathrm{pH}$ of each solution was determined at room temperature $\left(25^{\circ} \mathrm{C}\right)$ and recorded.
2.5.3. Determination of Solids Contents. Four (4) grams of hair washing formulation was placed onto a clean, dry evaporating dish. The evaporating dish holding the shampoo was weighed using electronic balance, and the total weight was recorded as $\mathrm{W}_{1}$. Then, the evaporating dish was placed on the hot plate at $50^{\circ} \mathrm{C}$ and was kept until the liquid content was completely evaporated. Finally, the cooled evaporating dish holding the solid content was weighed and recorded as $W_{2}$, and the percentage (\%) of the solid content was calculated as $\left[\left(W_{1}-W_{2}\right) \div W_{1}\right] \times 100$.

2.5.4. Measurement of Surface Tension. Surface tension measurements were carried out using a $10 \%(\mathrm{v} / \mathrm{v})$ solution of hair washing formulation prepared with sterile distilled water at $25^{\circ} \mathrm{C}$. The surface tension of each solution was measured by the stalagmometric method. Thus, the stalagmometer was thoroughly cleaned using chromic acid and sterile distilled water to remove any traces of greases and lubricants because they greatly affect surface tension. The surface tension was calculated using this formula $R^{2}=\left[\left(\left(W_{3}-W_{1}\right) \times N_{1}\right) \div\left(\left(W_{2}-W_{1}\right) \times\right.\right.$ $\left.N_{2}\right)$ ] $\times R_{1}$, where $W_{1}$ is the weight of empty beaker, $W_{2}$ is the weight of beaker with distilled water, $W_{3}$ is the weight of beaker with formulation solution, $N_{1}$ is the number of drops of distilled water, $N_{2}$ is the number of drops of formulation solution, $R_{1}$ is the surface tension of distilled water at $25^{\circ} \mathrm{C}$, and $R^{2}$ is the surface tension of shampoo solution at $25^{\circ} \mathrm{C}[41]$. 
2.5.5. Dirt Dispersion. Two drops $(0.10 \mathrm{~mL})$ formulation was added into a $100 \mathrm{~mL}$ test tube containing $10 \mathrm{~mL}$ sterile distilled water. Then, one drop $(0.05 \mathrm{~mL})$ of India ink was added to the test tube, stoppered, and shaken 10 times. The amount of ink in the foam was estimated as none, light, moderate, and heavy by three randomly selected volunteering students.

2.5.6. Rheological (Viscosity) Evaluations. The viscosities of the hair washing formulations were determined using the Brookfield Viscometer (Model DV-l Plus, LV, USA) set at different spindle speeds ranging from 0.3 to $10 \mathrm{rpm}$. Viscosity measurements were carried out using spindle T95 by maintaining the temperature at $25^{\circ} \mathrm{C}$ and the sizes of the containers holding formulation samples constant.

2.5.7. Foaming Ability and Foam Stability. The foaming ability of the formulations was determined using the cylinder shake method at $25^{\circ} \mathrm{C}$. Fifty $(50) \mathrm{mL}$ of the $1 \%(\mathrm{v} / \mathrm{v})$ solution of hair washing formulation was put into a $250 \mathrm{~mL}$ graduated cylinder. The cylinder was covered by hand, shaken 10 times, and left to stand for $1 \mathrm{~min}$ in a test tube rack. The volume of the foam was recorded at the end of $1 \mathrm{~min}$ standing. This represented the foaming ability. The foaming stability was, likewise, determined by measuring the volume of the foam at $1,2,3$, and 4 min after shaking and observing the decrement in foam volume [44].

2.5.8. Wetting Time Test. The wetting times of the hair washing formulations were determined using the canvas disc method with some modifications [38-40, 45]. One (1) inch diameter discs, weighing 0.45 grams, were cut out from a smooth garment (velvet). Also, $400 \mathrm{~mL}$ of $1 \%$ (v/v) solutions were prepared in a $500 \mathrm{~mL}$ graduated cylinder from all the formulations. Wetting time of each formulation was tested by floating a canvas disc on the graduated cylinder holding the $400 \mathrm{~mL}$ solution and recording the time required for the disk to start sinking using a stopwatch. The time required for the disc to start sinking was recorded as wetting time.

2.5.9. Evaluation of Conditioning Performance. Conditioning performances of the formulations were evaluated using the procedure developed by Boonme et al. [43] with some modifications. Ethiopian male hair cut was collected from barber shop and divided into $5 \mathrm{~g}$ mass. One $5 \mathrm{~g}$ mass served as control and another $5 \mathrm{~g}$ mass was washed with each formulation. Washing solution was prepared by mixing $1 \mathrm{~mL}$ of formulation and $50 \mathrm{~mL}$ of distilled water in a conical flask. Then, the $5 \mathrm{~g}$ hair mass was put into the flask, shaken for $2 \mathrm{~min}$, rinsed with $100 \mathrm{~mL}$ distilled water, placed in plastic sheet, and allowed to dry at room temperature. The control hair mass was washed with distilled water only. Finally, the smoothness and softness (i.e., conditioning performance) of the hair mass was estimated by blind touch test methods involving three randomly selected volunteering students. The students were blind folded and asked to touch (feel) the hair mass for its smoothness and softness, and rate it as poor, satisfactory, good, and excellent. They also visually inspected the hair mass for its glowing appearance and silkiness.

\section{Results and Discussion}

3.1. Phytochemistry of A. elegans Gel. Like many Aloe species, A. elegans is the source of many useful phytochemicals. The present phytochemical screening using methanol gel extracts of the species yielded positive results for anthraquinones, flavonoids, saponins, and tannins (Table 3). Another study reported the presence of terpenoids by using ethyl acetate extract [21].

GC-MS analysis of gel extract of $A$. elegans resulted in 12 compounds (Table 4, Figure 1). The compounds or their derivatives are used in formulating beauty and personal care products. Decanoic (capric) acid (1), dodecanoic (lauric) acid (2), hexadecanoic (palmitic) acid (8), (Z,Z)-9,12octadecadienoic (linoleic) acid (9), and phytol (11) are used in preparing personal care products such as soaps and detergents. Moreover, decanoic (capric) acid (1), tetradecanoic (myristic) acid (6), hexadecanoic (palmitic) acid (8), (Z,Z)9,12-octadecadienoic (linoleic) acid (9), and phytol (11) are used to formulate cosmetics and beauty products. Phytol (11) and octadecanoic (stearic) acid (12) are also important components in producing commercial shampoos and shaving creams. Furthermore, whereas compound $\mathbf{9}$ is important source of surfactants, compound $\mathbf{1 2}$ is used in saponification [46]. Similar fatty acids and essential oils were found in A. adigratana Reynolds [38].

\subsection{Evaluation of Hair Washing Formulations of A. elegans $\mathrm{Gel}$}

3.2.1. Sensory Assessment. Cosmetic products including hair washing shampoos have attractive appearance to the sensory observer. Sensory observation and simple measurements showed that the formulations were white and turbid with characteristically good odor without major difference from the commercial shampoo (Table 5). The white color of the formulations was due to the absence of the coloring agent. The color, turbidity, and odor of the shampoos did not change with increasing the proportion of the gel.

Formulations 1-4 containing 4-10 $\mathrm{mL}$ gel are thinner. Slightly thick formulation, such as the marketed shampoo, was produced with $10 \mathrm{~mL}$ of gel and 2 drops coconut oil in $\mathrm{F}_{5}$. Likewise, formulations with higher gel volume $(8-10 \mathrm{~mL})$ showed best consistency as the marketed shampoo. Varying the proportion of the gel did not bring about significant change in $\mathrm{pH}$ of the formulations-falling within the $\mathrm{pH}$ range of many marketed shampoos [38-40,47].

3.2.2. Quality Characteristics. Solid content, foam stability, dirt dispersion, surface tension, wetting time, and conditioning performance are the principal parameters used in the qualitative evaluation of shampoos. The physical characteristics of the hair washing laboratory formulations are summarized in Table 6. 
Table 3: Phytochemical screening of A. elegans leaf gel.

\begin{tabular}{lcccc}
\hline Phytochemicals & Tests & Inspection & Results & Reference \\
\hline Alkaloids & Wagner test & Brownish-red precipitate & - & {$[33]$} \\
Anthraquinones & Borntrager's test & Pink, red & + & + \\
Flavonoids & Lead acetate test & Yellow precipitate & + & $+34]$ \\
Saponins & Froth test & Foam & Dark-green & + \\
Tannins & Ferric chloride test & Reddish-brown & - \\
Terpenoids & Salkowski test & {$[36]$} & {$[37]$} \\
\hline
\end{tabular}

"+" sign indicates the presence, and "-" sign indicates absence of the chemical constituents.

TABle 4: Chemical composition of A. elegans leaf gel extract.

\begin{tabular}{|c|c|c|c|c|c|}
\hline SN & Name & Formula & Area & RT & $\%$ area \\
\hline 1 & Decanoic (capric) acid, methyl ester & $\mathrm{C}_{11} \mathrm{H}_{22} \mathrm{O}_{2}$ & 408,497 & 21.37 & 0.69 \\
\hline 2 & Dodecanoic (lauric) acid, methyl ester & $\mathrm{C}_{13} \mathrm{H}_{26} \mathrm{O}_{2}$ & $1,516,579$ & 26.55 & 2.55 \\
\hline 3 & Ar-tumerone & $\mathrm{C}_{15} \mathrm{H}_{20} \mathrm{O}$ & $3,401,566$ & 29.92 & 5.72 \\
\hline 4 & Tumerone & $\mathrm{C}_{15} \mathrm{H}_{22} \mathrm{O}$ & $2,691,776$ & 30.04 & 4.53 \\
\hline 5 & Curlone & $\mathrm{C}_{15} \mathrm{H}_{22} \mathrm{O}$ & $2,261,927$ & 30.79 & 3.81 \\
\hline 6 & Tetradecanoic (myristic) acid, methyl ester & $\mathrm{C}_{15} \mathrm{H}_{30} \mathrm{O}_{2}$ & $5,658,349$ & 31.16 & 9.52 \\
\hline 7 & 9-Methyltetradecanoic (9-methylmyristic) acid, methyl ester & $\mathrm{C}_{16} \mathrm{H}_{32} \mathrm{O}_{2}$ & 661,028 & 33.50 & 1.11 \\
\hline 8 & Hexadecanoic (palmitic) acid, methyl ester & $\mathrm{C}_{17} \mathrm{H}_{34} \mathrm{O}_{2}$ & $18,109,462$ & 36.55 & 30.47 \\
\hline 9 & (Z,Z)-9,12-octadecadienoic (linoleic) acid, methyl ester & $\mathrm{C}_{19} \mathrm{H}_{34} \mathrm{O}_{2}$ & $4,180,215$ & 43.76 & 7.03 \\
\hline 10 & (E)-9-octadecadienoic (elaidic) acid, methyl ester & $\mathrm{C}_{19} \mathrm{H}_{36} \mathrm{O}_{2}$ & $14,946,083$ & 44.09 & 25.14 \\
\hline 11 & Phytol & $\mathrm{C}_{20} \mathrm{H}_{40} \mathrm{O}$ & $1,229,919$ & 44.48 & 2.07 \\
\hline 12 & Octadecanoic (stearic) acid, methyl ester & $\mathrm{C}_{19} \mathrm{H}_{38} \mathrm{O}_{2}$ & $4,376,317$ & 45.12 & 7.36 \\
\hline
\end{tabular}

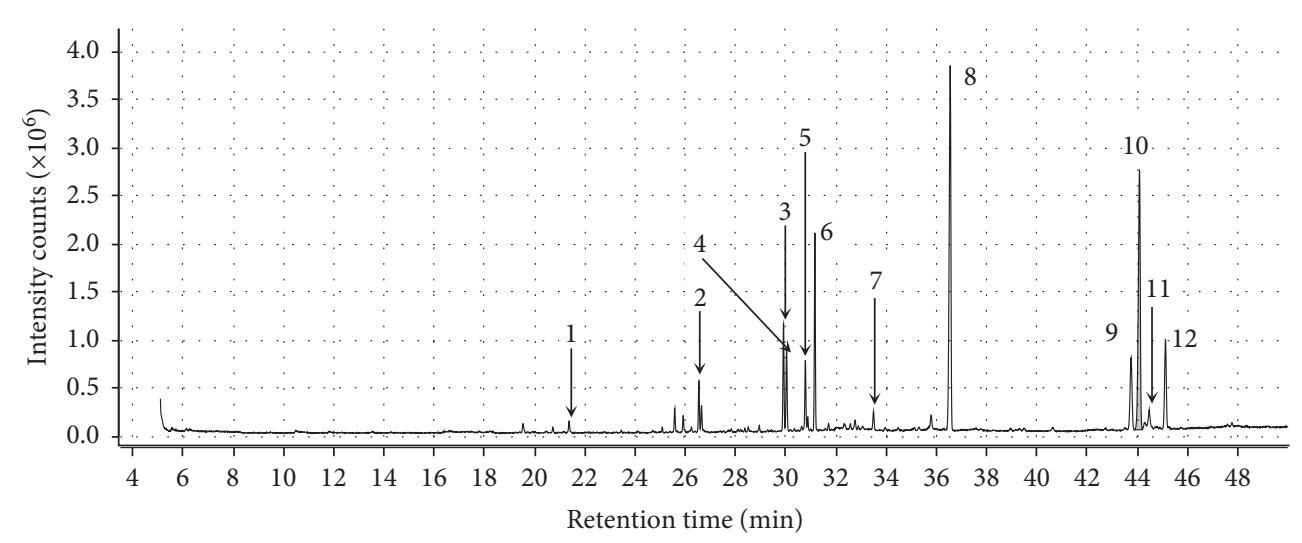

FIgURE 1: GC-MS analysis of A. elegans leaf gel extract.

TABle 5: Physical inspection of hair washing formulations of A. elegans gel.

\begin{tabular}{llllcrrr}
\hline Formulations & Color & Clarity & Odor & Consistency & Spreadability & $\mathrm{pH}$ & Temperature $\left({ }^{\circ} \mathrm{C}\right)$ \\
\hline $\mathrm{F}_{1}(4 \mathrm{~mL})$ & White & Turbid & Characteristic & Thin & Good & 6.5 & 25 \\
$\mathrm{~F}_{2}(6 \mathrm{~mL})$ & White & Turbid & Characteristic & Thin & Good & 6.6 & 25 \\
$\mathrm{~F}_{3}(8 \mathrm{~mL})$ & White & Turbid & Characteristic & Thin & Best & 6.6 & 25 \\
$\mathrm{~F}_{4}(10 \mathrm{~mL})$ & White & Turbid & Characteristic & Thin & Best & 6.5 & 25 \\
$\mathrm{~F}_{5}(10 \mathrm{~mL})$ & White & Turbid & Characteristic & Slightly thick & Best & 6.4 & 25 \\
Marketed & Green & Turbid & Characteristic & Slightly thick & Best & 6.7 \\
\hline
\end{tabular}

(1). Solid Content. The solid contents of our formulations ranged from $23 \%$ to $29 \%$ (Table 6). Quality shampoos are preferred to have the solid content of $20 \%-30 \%$. Shampoos with lower solid content are thin and watery while those with higher solid content are thick and greasy. Whereas thin shampoos drain off the hair quickly, the thick ones are difficult to work with $[39,41,48,49]$. Increasing the proportion of the gel from $2 \mathrm{~mL}$ to $10 \mathrm{~mL}$ consistently led to the raising of the solid contents of the formulations. Thus, the solid content of A. elegans-based hair washing 
TABLE 6: Evaluations of A. elegans hair washing formulations.

\begin{tabular}{lccccccc}
\hline Formulation & $\begin{array}{c}\text { Solid content } \\
(\%)\end{array}$ & $\begin{array}{c}\text { Foam } \\
\text { stability }\end{array}$ & $\begin{array}{c}\text { Dirt in the } \\
\text { foam }\end{array}$ & $\begin{array}{c}\text { Surface tension } \\
(\text { dynes } / \mathrm{cm})\end{array}$ & $\begin{array}{c}\text { Wetting time } \\
(\text { sec. })\end{array}$ & $\begin{array}{c}\text { Conditioning } \\
\text { performance }\end{array}$ & $\begin{array}{c}\text { Temp. } \\
\left({ }^{\circ} \mathrm{C}\right)\end{array}$ \\
\hline $\mathrm{F}_{1}(4 \mathrm{~mL})$ & 23 & Very good & Not detected & 38 & 142 & Good \\
$\mathrm{F}_{2}(6 \mathrm{~mL})$ & 24 & Very good & Not detected & 37 & 150 & 25 \\
$\mathrm{~F}_{3}(8 \mathrm{~mL})$ & 26 & Very good & Not detected & 36 & 152 & Good \\
$\mathrm{F}_{4}(10 \mathrm{~mL})$ & 28 & Very good & Not detected & 34 & 153 & Good \\
$\mathrm{F}_{5}(10 \mathrm{~mL})$ & 29 & Very good & Not detected & 33 & 160 & Good & Good \\
Marketed & 26 & Very good & Not detected & 32 & 185 & 25 \\
\hline
\end{tabular}

TABle 7: Viscosities of A. elegans gel formulations.

\begin{tabular}{lcccccc}
\hline Formulations & Viscosity (poise) & Speed $(\mathrm{rpm})$ & \% FSR & Shear stress & Stress rate & Temperature $\left({ }^{\circ} \mathrm{C}\right)$ \\
\hline $\mathrm{F}_{1}(4 \mathrm{~mL})$ & 13.56 & 60 & 37.89 & 112.87 & 899.99 & 25 \\
$\mathrm{~F}_{2}(6 \mathrm{~mL})$ & 26.47 & 60 & 66.67 & 168.38 & 899.99 & 25 \\
$\mathrm{~F}_{3}(8 \mathrm{~mL})$ & 26.66 & 60 & 69.52 & 169.94 & 899.99 & 25 \\
$\mathrm{~F}_{4}(10 \mathrm{~mL})$ & 26.73 & 60 & 69.11 & 169.72 & 899.99 & 25 \\
$\mathrm{~F}_{5}(10 \mathrm{~mL})$ & 26.45 & 60 & 68.78 & 169.11 & 899.99 & 25 \\
Marketed & 26.92 & 60 & 69.98 & 169.91 & 899.99 & 25 \\
\hline
\end{tabular}

formulations can be easily decided by fixing the proportion of the gel [38].

(2). Foam Ability and Stability. Good shampoos have bigger and stable foams upon shaking. Foam volume and stability are principal quality parameters of shampoos [50]. All our formulations were very good in terms of volume and stability similar to the marketed $A$. vera shampoo. All the formulations were compact, uniform, and stable maintaining their volumes for more than four minutes. Similar findings were reported with lab-made A. adigratana formulations [38].

(3). Dirt Dispersion. Shampoos that concentrate dirt or stain in their foams are regarded as low quality [39, 40, 51]. But good shampoos and detergents concentrate the dirt in the water. Since the dirt is often water insoluble, it is removed by the help of surfactants present in the shampoos and detergents. The present study showed that all the formulations yielded clean foams with no dirt like the marketed shampoo (Table 6). These imply that the linoleic acid (Compound 9) present in the leaf gel of the species is an important source of surfactants. Similar observations were reported elsewhere $[38,48,52]$.

(4). Surface Tension. Good shampoos and detergents reduce the surface tension of pure water from 72 dynes/cm to below 40 dynes $/ \mathrm{cm}$ at $25^{\circ} \mathrm{C}$ [53] to improve detergency [54]. Our study resulted in $A$. elegans formulations with surface tension ranging from 33 (10 mL gel) to 38 dynes $/ \mathrm{cm}(4 \mathrm{~mL}$ gel) at $25^{\circ} \mathrm{C}$ (Table 6). Other researchers also formulated herbal shampoos with surface tension between 30 and 40 dynes $/ \mathrm{cm}$ $[38,49,50]$. The decrease of the surface tension of the formulations with increasing the proportion of gel might be accounted for the amount of surfactants (linoleic acid) in the gel. Increasing the proportion of the A. elegans gel resulted in formulations with surface tension comparable to that of the marketed shampoo [38].

(5). Wetting Ability. Shampoos with high concentration of surfactants have better wetting abilities. Canvas disc tests resulted that our $A$. elegans hair washing formulations have lower wetting time $(142-160 \mathrm{sec})$ compared to the market A. vera shampoo $(185 \mathrm{sec})$ (Table 6$)$. Higher concentration of detergents causes lower wetting time [38, 42].

(6). Conditioning Performance. The conditioning performances of shampoos are largely affected by their chemical properties. They are, therefore, formulated by enriching them with conditioning agents. The agents deposit, adhere, or adsorb onto proteins of hair and improve its manageability. They also reduce hair static and make it soft and smooth [42]. Samples of Ethiopian cut hair washed with the formulations became smooth and soft as compared to that washed with pure water. Thus, all the formulations demonstrated that good conditioning performance rendered the hair samples glowing, soft, silky, and manageable. The conditioning performance of the formulations may be accounted to the capric (1), lauric (2), myristic (6), palmitic (8), and stearic (12) acids detected in the gel. Fatty acids with 8-18 carbons are used in formulating shampoos and conditioners $[46,55]$.

(7). Viscosity. Viscosity affects the spreadability and consistency of shampoos. Good shampoos spread easily upon application and remain consistent until use [41]. The viscosities of the formulations of the present study ranged from 13.56 ( $4 \mathrm{~mL}$ gel) to 26.73 poise $(10 \mathrm{~mL}$ gel). Viscosities of the formulations prepared using $6-10 \mathrm{~mL}$ of gel are close to that of the marketed shampoo (26.45 poise) (Table 7$)$. The viscosities of the formulations were increased by increasing the amount of the gel. The moisture contents of the formulations 
were also ranged between 95\% and 96\%. Therefore, A. elegans formulations with higher proportion of gel were found to have comparable viscosities and other properties with the marketed shampoo [38-40].

\section{Conclusion}

The phytochemical screening and GC-MS analysis of methanol extract revealed that $A$. elegans gel is a good source of key chemical constituents used in the formulation of beauty, cosmetics, detergent, and personal care products. Likewise, the lab-made hair washing formulations prepared and evaluated in this study exhibited desirable properties recommended for similar products. Evaluation through sensory observation and physicochemical tests revealed that A. elegans gel demonstrated good potential for formulating hair shampoos. Thus, future studies may aim at establishing the complete phytochemical profile of the plant and developing refined shampoo-formulation protocol. Further work on this threatened species would encourage efforts towards its conservation and sustainable use.

\section{Appendix}

\section{Instrument Control Parameters of GC-MS}

D:|MassHunter $\backslash G C M S \backslash 1 \backslash$ methods $\backslash$ Fatty Acid_A. elgans_DB5MS 10.M Wed Jul 17 11:39:33 2019; control information: sample inlet, GC; injection source, GC ALS; injection location, front, and mass spectrometer, enabled. GC: oven temperature; set point $\mathrm{On}$ (initial) $60^{\circ} \mathrm{C}$; hold time, $0 \mathrm{~min}$ and post run, $50^{\circ} \mathrm{C}$. Program: \#1 Rate $3^{\circ} \mathrm{C} / \mathrm{min}$; \#1 Value $110^{\circ} \mathrm{C}$; \#1 Hold Time $0 \mathrm{~min}$; \#2 Rate $10^{\circ} \mathrm{C} / \mathrm{min}$; \#2 Value $140^{\circ} \mathrm{C}$; $\# 2$ Hold Time $1 \mathrm{~min}$; \#3 Rate $5^{\circ} \mathrm{C} / \mathrm{min}$; \#3 Value $195^{\circ} \mathrm{C}$; \#3 Hold Time $10 \mathrm{~min}$; \#4 Rate $5^{\circ} \mathrm{C} / \mathrm{min}$; \#4 Value $225^{\circ} \mathrm{C}$; \#4 Hold Time $6 \mathrm{~min}$; \#5 Rate $20^{\circ} \mathrm{C} / \mathrm{min}$; \#5 Value $250^{\circ} \mathrm{C}$ and $\# 5$ Hold Time 4 min.

\section{Data Availability}

The datasets used and/or analyzed during the current study are available from the corresponding author upon reasonable request.

\section{Conflicts of Interest}

The authors declare that they have no conflicts of interest.

\section{Authors' Contributions}

All the authors were involved in planning and designing of the study. In addition, DBS was involved in the conceptualizing the study, securing funding, supervising the study, collecting specimens, organizing the data, and preparing the submitted manuscript; GGB was involved in developing the experimental procedures, collecting specimens, running the experiments, organizing the data, and writing first draft of the manuscript; AGH, AA, HBA, MYW, and HTT were involved in running the experiments and preparing inputs; $A M$ was involved in verifying the experimental procedures and reviewing the draft manuscript; HAG, MGT, and HGK were involved in data organization.

\section{Acknowledgments}

The authors are highly thankful for the administration support by the Office of the Postgraduate Programs and Research of Mekelle University, the Office of Research and Community Services of Mekelle Institute of Technology, the Office of the Dean of Mekelle Institute of Technology, and the Department of Biological and Chemical Engineering, Mekelle Institute of Technology. The collection, analysis, interpretation of data, and the writing of this manuscript were funded by the Mekelle University, Ethiopia, through grant number CRPO/MIT/LARGE/001/09.

\section{References}

[1] IASC, Aloe Vera: A Long, Illustrious History Dating From Biblical Times, The International Aloe Science Council, Silver Spring, MD, USA, 2002, http://docs8.chomikuj.pl/ 305768720,PL,0,0,aloebook.pdf.

[2] N. Dwivedi, A. Indiradevi, K. Asha, N. Asokan, and A. Suma, "A protocol for micropropagation of Aloe vera L. (Indian Aloe)-a miracle plant," Research in Biotech, vol. 5, pp. 1-5, 2014.

[3] S. Demissew and I. Nordal, Lilies and Aloes of Ethiopia and Eritrea, Shama Books, Addis Ababa, Ethiopia, 2nd edition, 2010.

[4] S. Demissew, I. Friis, T. A. Feye et al., "Four new species of Aloe (Aloaceae) from Ethiopia, with notes on the ethics of describing new taxa from foreign countries," Kew Bulletin, vol. 66, no. 1, pp. 111-121, 2011.

[5] O. Weber, "Aloe elegans, The IUCN red list of threatened species 2013: e.T201355A27018 15,” 2013.

[6] P. Sahu, D. Giri, R. Singh et al., "Therapeutic and medicinal uses of Aloe vera: a review," Pharmacology \& Pharmacy, vol. 4, pp. 599-610, 2013.

[7] J. Adelberg and J. Naylor-Adelberg, "Effects of cytokinin on multiplication and rooting of Aloe barbadensis during micropropagation on agar and liquid media," Journal of Medicinally Active Plants, vol. 1, pp. 1-26, 2012.

[8] H. Yao, Y. Chen, L. Huang, W. Chen, and X. Lin, "Promotion proliferation effect of polysaccharide from Aloe barbadensis Miller on human fibroblasts in vitro," International Journal of Biological Macromolecules, vol. 45, no. 2, pp. 152-156, 2009.

[9] G. Periasamy, S. Kassa, B. Sintayehu, G. Mebrahtom, G. Geremedhin, and A. Karim, "Cosmetic use of Aloe vera-a review," World Journal of Pharmacy and Parmaceutical Sciences, vol. 3, no. 5, pp. 342-458, 2014.

[10] A. O. Adesuyi, O. A. Awosanya, F. B. Adaramola, and A. I. Omeonu, "Nutritional and phytochemical screening of Aloe barbadensis," Current Research of Journal Biological Sciences, vol. 4, no. 1, pp. 4-9, 2012.

[11] E. R. Rodríguez, J. D. Martín, and C. D. Romero, "Aloe vera as a functional ingredient in foods," Critical Reviews in Food Science and Nutrition, vol. 50, no. 4, pp. 305-326, 2010.

[12] G. O. M. Elhassan, A. Adhikari, S. Yousuf et al., "Phytochemistry and antiglycation activity of Aloe sinkatana reynolds," Phytochemistry Letters, vol. 5, no. 4, pp. 725-728, 2012.

[13] W. Chen, B. V. Wyk, I. Vermaak, and A. M. Viljoen, "Cape aloes-A review of the phytochemistry, pharmacology and 
commercialisation of Aloe ferox," Phytochem. Lett.vol. 5, no. 1, pp. 1-12, 2012.

[14] M. K. Park, J. H. Park, N. Y. Kim et al., "Analysis of 13 phenolic compounds in Aloe species by high performance liquid chromatography," Phytochemical Analysis, vol. 9, no. 4, pp. 186-191, 1998.

[15] D. I. Sánchez-Machado, J. Lopez-Cervantes, R. Sendon, and A. Sanches-Silva, "Aloe vera: ancient knowledge with new frontiers," Trends in Food Science \& Technology, vol. 61, pp. 94-102, 2017.

[16] A. A. Maan, A. Nazir, M. Kashif et al., "The therapeutic properties and applications of Aloe vera: a review," Journal of Herbal Medicine, vol. 12, pp. 1-10, 2018.

[17] B. Salehi, S. Albayrak, H. Antolak et al., "Aloe genus plants: from farm to food applications and phytopharmacotherapy," International Journal of Molecular Sciences, vol. 19, p. 2843, 2018.

[18] L. B. Lidia, D. B. Sibhatu, M. Seid et al., "Comparative antimicrobial activities of the gel, leaf and anthraquinone fractionates of four Aloe species (Aloe camperi, Aloe elegans, Aloe eumassawana and Aloe schoelleri)," Advances in Microbiology, vol. 9, no. 2, pp. 139-150, 2019.

[19] G. H. Brhane, V. K. Gopalakrishnan, Z. Hagos, M. Hiruy, K. Devaki, and K. K. Chaithanya, "Phytochemical screening and in vitro antioxidant activities of ethanolic gel extract of Aloe adigratana Reynolds," Journal of Pharmacy Research, vol. 12, no. 1, pp. 13-19, 2018.

[20] M. Tsegay, Y. Tewabe, D. Bisrat, and K. Asres, "In vivo antiinflammatory activity of two anthrones from the leaves of Aloe adigratana Reynolds and Aloe elegans Todaro," Ethiopian Pharmaceutical Journal, vol. 34, no. 1, pp. 1-8, 2018.

[21] M. Habtemariam and G. Medhanie, "Screening of biologically active constituents from leaves of Aloe elegans and their antimicrobial activities against clinical pathogens," African Journal of Microbiology Research, vol. 11, no. 8, pp. 366-371, 2017.

[22] B. Girma, D. Bisrat, and K. Asres, "Antimalarial evaluation of the leaf latex of Aloe citrina and its major constituents," Ancient Science of Life, vol. 34, no. 3, pp. 43-47, 2015.

[23] G. Gebremedhin, D. Bisrat, and K. Asres, "Isolation, characterization, and in vivo antimicrobial evaluation of anthrones from leaf latex of Aloe percrassa Todaro," Journal of Natural Remedies, vol. 14, no. 2, pp. 1-7, 2014.

[24] W. Gemechu, D. Bisrat, and K. Asres, "Antimalarial anthrone and chromone from the leaf latex of," Ethiopian Pharmaecutical Journal, vol. 30, no. 1, pp. 1-9, 2014.

[25] G. Minale, D. Bisrat, K. Asres, and A. Mazumder, "In vitro antimicrobial activities of anthrones from the leaf latex of Aloe sinana Reynolds," International Journal of Green Pharmacy, vol. 8, no. 1, pp. 7-12, 2014.

[26] A. Suleyman, N. Gnanasekaran, and S. Daniel, "Amelioration of streptozotocin-induced hyper-glycemia and dyslipidemia through Aloe debrana," International Journal of Pharmacy and Pharmaceutical Sciences, vol. 7, no. 2, pp. 290-293, 2014.

[27] G. Asamenew, D. Bisrat, A. Mazumder, and K. Asres, "In vitro antimicrobial and antioxidant activities of anthrone and chromone from the latex of aloe harlana Reynolds," Phytotherapy Research, vol. 25, no. 12, pp. 1756-1760, 2011.

[28] B. Paulos, D. Bisrat, T. Gedif, and K. Asres, "Antimalarial and antioxidant activities of the leaf exudates and a naphthalene derivative from Aloe otallensis Baker," Ethiopian Pharmaceutical Journal, vol. 29, no. 2, pp. 100-107, 2011.

[29] T. Deressa, Y. Mekonnen, and A. Animut, "In vivo antimalarial activities of Clerodendrom myricoides, Dodonaea angustifolia and Aloe debrana against Plasmodium berghei," Ethiopian Journal of Health and Development, vol. 24, pp. 25-29, 2010.

[30] E. Dagne and M. Alemu, "Constituents of the leaves of four Aloe species from Ethiopia," Bulletin of the Chemical Society of Ethiopia, vol. 5, pp. 87-91, 1991.

[31] B. Yemane and G. Medhanie, "Ethnobotanical study of medicinal plants in sub-zoba debarwa, zoba debub, Eritrea," Eritrean Journal of Science and Engineering, vol. 2, no. 1, pp. 65-89, 2016.

[32] T. Beyene, "Ethnobotany of medicinal plants in erob and gulomekada districts, Eastern zone of Tigrai Region, Ethiopia," Ph.D Dissertation Monograph, Addis Ababa University, Addis Ababa, Ethiopia, 2015.

[33] J. Parekh, N. Karathia, and S. Chanda, "Evaluation of antibacterial activity and phytochemical analysis of Bauhinia variegata L. bark," African Journal of Biomedical Research, vol. 9, pp. 53-56, 2006.

[34] T. Kebede, F. Kibret, M. Fikre, and E. Milkyas, "Phytochemical screening and characterization of olean-18-ene type triterpeniod from the roots of," Science, Technology and Arts Research Journal, vol. 4, no. 1, pp. 91-94, 2015.

[35] S. Bhandary, S. Kumari, V. Bhat, S. Sherly, and M. P. Bekal, "Preliminary phytochemical screening of various extracts of Punica granatum peel, whole fruit and seeds," Journal of Health Sciences, vol. 2, no. 4, pp. 35-38, 2012.

[36] A. Abebayehu, F. Mammo, and B. Kibret, "Isolation and characterization of terpenes from leaves of Croton macrostachyus (Bissana)," Journal of Medicinal Plants Research, vol. 10, no. 19, pp. 256-269, 2016.

[37] A. Sofowora, Medicinal Plants and Traditional Medicine in Africa, pp. 142-145, John Wiley \& Sons, Chichester, UK, 1982.

[38] D. B. Sbhatu, G. G. Berhe, A. G. Hndeya et al., "Formulation and physicochemical evaluation of lab-based Aloe adigratana Reynolds shampoos," International Journal of Analytical Chemistry, vol. 2020, Article ID 6290617, 7 pages, 2020.

[39] K. Al Badi and S. A. Khan, "Formulation, evaluation and comparison of the herbal shampoo with the commercial shampoos," Beni-Suef University Journal of Basic and Applied Sciences, vol. 3, no. 4, pp. 301-305, 2014.

[40] Y. Pounikar, P. Jain, N. Khurana, L. K. Omray, S. Patil, and A. Gajbhiye, "Formulation and characterization of Aloe vera cosmetic herbal hydrogel," International Journal of Pharmacy and Pharmaceutical Sciences, vol. 4, no. 4, pp. 85-86, 2012.

[41] B. T. AlQuadeib, E. K. D. Eltahir, R. A. Banafa, and L. A. AlHadhairi, "Pharmaceutical evaluation of different shampoo brands in local Saudi market," Saudi Pharmaceutical Journal, vol. 26, pp. 98-106, 2018.

[42] P. R. Shinde, A. U. Tatiya, and S. J. Surana, "Formulation, development and evaluation of herbal antidandruff shampoo," International Journal of Research in Cosmetic Science, vol. 3, no. 2, pp. 25-33, 2013.

[43] P. Boonme, N. Pakpayat, K. Yotmanee, S. Kunlawijitrungsee, and D. Maneenuan, "Evaluation of shampoos containing silicone quaternary microemulsions," Journal of Applied Pharmaceutical Science, vol. 1, no. 1, pp. 59-63, 2011.

[44] A. R. Manikar and C. I. Jolly, "Evaluation of commercial herbal shampoos," International Journal of Cosmetic Science, vol. 22, no. 5, pp. 385-392, 2000.

[45] K. Klein, "Evaluation of shampoo foam," Cosmetics and Toiletry Management, vol. 119, no. 10, pp. 32-35, 2004.

[46] NIH (US National Library of Medicine), "National center for biotechnology information, (National Institute of Health)," http://pubchem.ncbi.nlm.nih.gov, 2020. 
[47] J. Tarun, J. Susan, J. Suria, V. J. Susan, and S. Criton, "Evaluation of $\mathrm{pH}$ of bathing soaps and shampoos for skin and hair," Indian Journal of Dermatology, vol. 59, no. 5, pp. 442-444, 2014.

[48] R. O. Bakr, R. I. Amer, M. A. A. Fayed, and T. I. M. Ragab, “A completely polyherbal conditioning and antioxidant shampoos: a phytochemical study pharmaceutical evaluation," Journal of Pharmacy and Bioallied Sciences, vol. 11, no. 2, pp. 105-115, 2019.

[49] A. Vijayalakshmi, S. Sangeetha, and N. Ranjith, "Formulation and evaluation of herbal shampoo," Asian Journal of Pharmaceutical and Clinical Research, vol. 11, no. 4, pp. 121-124, 2018.

[50] R. Deeksha, P. Malviya, and S. Kumar, "Evaluation of marketed shampoo (synthetic and natural) for their hair cleansing, dirt dispersion, wetting time, solid content and foaming capacity properties," Global Journal of Pharmacology, vol. 8, pp. 490-493, 2014.

[51] A. H. Saad and R. B. Kadhim, "Formulation and evaluation of herbal shampoo from Ziziphus spina-christi leaves extract," International Journal of Research in Ayurveda \& Pharmacy, vol. 2, no. 6, pp. 1802-1806, 2011.

[52] J. Yang, "Hair care cosmetics," in Cosmetic Science and Technology: Theoretical Principles and Application, K. Sakamoto, R. Y. Lochhead, H. I. Maibach, andY. Yamashita, Eds., pp. 601-615, Elsevier, Amsterdam, Netherlands, 2017.

[53] S. Ireland, K. Carlino, L. Gould et al., "Shampoo after craniotomy: a pilot study," Canadian Journal of Neuroscience, vol. 29, no. 1, pp. 14-19, 2007.

[54] A. Kumar and R. R. Mali, "Evaluation of prepared shampoo formulations and compare formulated shampoo with marketed shampoos," International Journal of Pharmaceutical Sciences Review and Research, vol. 3, no. 1, pp. 120-126, 2010.

[55] B. J. Fealy and A. I. Reinbold, "Shampoo and conditioning composition," US Patent 5656257A, https://patents.google. com/patent/US5656257A/en, 1995. 